\title{
ZW10 interacting kinetochore protein may serve as a prognostic biomarker for human breast cancer: An integrated bioinformatics analysis
}

\author{
HAN-NING LI* , WEI-HONG ZHENG* ${ }^{*}$ YA-YING DU, GE WANG, \\ MENG-LU DONG, ZHI-FANG YANG and XING-RUI LI \\ Department of Thyroid and Breast Surgery, Tongji Hospital, Tongji Medical College of Huazhong \\ University of Science and Technology, Wuhan, Hubei 430030, P.R. China
}

Received June 21, 2019; Accepted November 19, 2019

DOI: $10.3892 / \mathrm{ol} .2020 .11353$

\begin{abstract}
ZW10 interacting kinetochore protein (ZWINT) is an essential component for the mitotic spindle checkpoint and has been reported to be upregulated in numerous types of human cancer. Nonetheless, its role in breast cancer (BC) remains unclear. Herein, it was demonstrated that the expression of ZWINT was significantly higher in BC than in normal breast tissues, on the basis of integrated analysis of bioinformatics studies, cancer database analyses and immunohistochemical detection. Elevated ZWINT levels were associated with a number of clinicopathological characteristics in patients with BC. These characteristics include: i) Positive human epidermal growth factor receptor 2 expression; ii) triple-negative $\mathrm{BC}$; iii) younger age; iv) basal-like subtype; and v) greater Scarff-Bloom-Richardson grades. Additionally, prognostic analysis indicated that shorter relapse-free survival, overall survival and metastatic relapse-free survival may be associated with high ZWINT expression. A total of 16 pathways associated with high ZWINT expression, including Myc targets V1/2, DNA repair and mitotic spindle pathways, were identified using Gene Set Enrichment Analysis. In addition, a positive correlation between cyclin-dependent kinase 1 (CDK1) and ZWINT mRNA expression was identified by co-expression analysis. The present study suggested that ZWINT may serve as an effective prognostic biomarker for BC. In addition, ZWINT may be implicated in the CDK1-mediated initiation
\end{abstract}

Correspondence to: Dr Zhi-Fang Yang or Dr Xing-Rui Li, Department of Thyroid and Breast Surgery, Tongji Hospital, Tongji Medical College of Huazhong University of Science and Technology, 1095 Jie Fang Avenue, Wuhan, Hubei 430030, P.R. China

E-mail: yangzhifangtj@163.com

E-mail: lixingrui@tjh.tjmu.edu.cn

*Contributed equally

Key words: ZW10 interacting kinetochore protein, bioinformatics analysis, breast cancer, prognosis and progression of $\mathrm{BC}$. However, further research is required to understand the role of ZWINT in BC.

\section{Introduction}

Breast cancer (BC) is a common malignancy among women. According to recent cancer statistics, 2.1 million women worldwide were diagnosed with $\mathrm{BC}$ and $\sim 627,000$ individuals died from the condition in 2018 (1). The prognosis of patients with $\mathrm{BC}$ has substantially improved in recent decades owing to the rapid advancement in diagnostic methods and individualized treatments. Nevertheless, this disease poses a severe threat to female health $(2,3)$. Routine diagnosis and treatment are rarely effective in certain patients due to the intratumor heterogeneity of $\mathrm{BC}$. Therefore, the identification of novel and more reliable molecular biomarkers for the prediction of outcomes and targeted treatments for BC is crucial.

As part of the kinetochore complex, ZW10 interacting kinetochore protein (ZWINT) is required for the mitotic spindle checkpoint (4). The majority of studies have proposed that ZWINT acts as a structural protein, which is part of the inner kinetochore scaffold and recruits zeste white 10, which is also a centromere protein, to the kinetochore $(5,6)$. Upregulation of ZWINT has been observed in numerous types of cancer, including ovarian and hepatocellular cancer, as well as glioblastoma, and is indicative of a worse prognosis (7-9). ZWINT depletion has been demonstrated to attenuate cell proliferation in 293-T and BC MCF-7 cells via Terf/tripartite motif containing 17 (TRIM17) signaling (10). In addition, abnormal expression of ZWINT has been reported to be associated with chromosomal instability and poor clinical outcomes in certain types of cancer (11). Furthermore, downregulated expression of ZWINT, mediated by the inhibition of cyclooxygenase- 2 , has been reported to impede the proliferation of prostate cancer cells via prostaglandin E receptor-1 signaling (12). These results suggested that ZWINT may serve an essential role in cancer progression and development.

Since the expression and clinical implication of ZWINT have not been comprehensively investigated in human BC, the current study examined the significance of ZWINT expression in human $\mathrm{BC}$ via bioinformatics analysis. The aim of 
the present study was to evaluate the expression profile, roles and accuracy of ZWINT as a biomarker for the long-term prognostic prediction of $\mathrm{BC}$ through pooling and analyzing currently available data.

\section{Materials and methods}

Tissue specimens and immunohistochemistry (IHC). BC and adjacent normal breast tissue specimens were collected from 62 patients who had been treated at the Tongji Hospital, Tongji Medical College of Huazhong University of Science and Technology (Wuhan, China) between September 2016 and June 2018. The patients that participated in the study had not received chemotherapy, radiotherapy, targeted therapy or other treatment prior to surgery. All patients in this study were women and were aged between 28 and 77 years (median age, 47 years). Written informed consent was obtained from all patients and the experimental protocol was approved by the Ethics Committee of Tongji Hospital, Tongji Medical College of Huazhong University of Science and Technology. The collected specimens were immediately fixed with $10 \%$ neutral formaldehyde for $12 \mathrm{~h}$ at room temperature. The fixed specimens were paraffin-embedded and cut into $4 \mu \mathrm{m}$ thick sections. IHC was conducted using Polink-2 plus ${ }^{\circledR}$ Polymer HRP Detection system (cat. no. PV-0023; BIOSS) according to the manufacturer's instructions. Sections were incubated with the primary antibody against ZWINT (cat. no. bs-7852R; BIOSS;1:200) at $4^{\circ} \mathrm{C}$ overnight, and with horseradish peroxidase-conjugated anti-rabbit immunoglobulin $\mathrm{G}$ (cat. no. bs-0295D-HRP; BIOSS; $1: 500$ ) at $37^{\circ} \mathrm{C}$ for $20 \mathrm{~min}$. The specimens were examined using an Olympus BX-51 microscope (Olympus, Corporation; magnification, x200) by two experienced pathologists. Results were scored according to the staining intensity and the percentage of positive cells on a 3- and 4-point scale. Staining intensity was graded as follows: 0 , negative; 1 , weak; 2 , moderate; or 3 , strong. The ratio of stained positive cells was scored as follows: 0 , no staining; 1 , $\leq 25 \% ; 2,26-50 \% ; 3,51-75 \%$; and 4, $>75 \%$. The total score was calculated as the sum of the intensity and percentage scores. Additionally, for semi-quantitative analysis, a score $\leq 4$ was considered to indicate low ZWINT expression and a score $>4$ high ZWINT expression.

Gene Expression Profiling Interactive Analysis(GEPIA)-based cancer data analysis. GEPIA (http://gepia.cancer-pku.cn/) analysis based on The Cancer Genome Atlas (TCGA) and the Genotype-Tissue Expression, which contains a large number of RNA sequencing data for cancer and normal tissues, was conducted to examine the mRNA expression levels of ZWINT in $\mathrm{BC}$ and adjacent normal tissues (13).

Oncomine database analysis. Data regarding the transcription levels of ZWINT in BC were retrieved from the Oncomine database (https://www.oncomine.org/), a cancer research database that contains a large number of datasets and samples, on the basis of microarray and high-throughput sequencing. A fold change $>2, \mathrm{P}<1 \times 10^{-4}$ and genes ranking in the top $10 \%$, with simultaneous data restricted to mRNA were set as significance cut-off levels. Four datasets [TCGA Breast (14), Curtis Breast (15), Ma Breast (16) and Richardson Breast (17)] were used to analyze the differential expression of ZWINT in multiple pathological types of $\mathrm{BC}$ and normal breast tissue.

Expression levels of ZWINT and clinical outcomes of BC. mRNA expression of ZWINT in different types of molecular and clinicopathological BC, and its association with prognosis were evaluated by employing Breast Cancer Gene-Expression Miner (version 4.1; bc-GenExMiner) which is a mining tool and a web source of published BC genomic data $(18,19)$. A P-value indicating statistically significant differences among groups (age, nodal status, ER, PR, Her-2, SBR grade, triple negative status and basal-like status) was generated using Welch's test followed by the Dunnett-Tukey-Kramer's test. Moreover, Kaplan-Meier Plotter (https://kmplot.com/), which is an online database that contains data from 5,143 patients with BC, 2,437 patients with lung cancer, 1,816 patients with ovarian cancer, 1,065 patients with gastric cancer and 364 patients with liver cancer combined with relapse-free survival (RFS) and overall survival (OS) data (20), was used to assess the relationship between the transcription levels of ZWINT and OS or RFS among patients with BC. Specifically, clinical samples were divided into high expression and low expression groups in terms of the median expression value of ZWINT. Subsequently, the log rank P-value and hazard ratio (HR) with 95\% confidence interval (CI) were calculated. In addition, the impact of ZWINT on metastatic relapse-free survival (MRFS) and the risk of metastatic relapse (MR) of $\mathrm{BC}$ patients were evaluated in all cohorts in bc-GenExMiner pooled by means of univariate Cox regression model, and were illustrated with a Kaplan-Meier curve and a forest plot, respectively.

Mutation and copy number variation (CNV) analysis of ZWINT. Mutations of ZWINT were evaluated using the Catalogue of Somatic Mutations in Cancer (COSMIC) database, which is a comprehensive resource of somatic mutations identified in numerous types of human cancer $(21,22)$. The distribution of various mutations was included and presented in the form of a pie chart. In addition, the cBio Cancer Genomics Portal (cBioPortal) (http://cbioportal.org) database was used to examine the alteration frequency of ZWINT mutations and CNVs in BC $(23,24)$. The following data were used in cBioPortal: i) Breast Cancer [MSK, Cancer Cell 2018 (25)] ii) Breast Cancer [METABRIC (26)] iii): Breast [BCCRC 2012 (27)] iv): Breast [Broad 2012 (28)] v): Breast [Sanger (29)] vi) Breast [TCGA (30)] vii): Breast [BCCRC Xenograft (31)]; viii) BRCA [INSERM 2016 (32)].

Gene set enrichment analysis (GSEA). The functional role of ZWINT was determined by performing GSEA. GSEA acts as a computational tool to evaluate whether a pre-defined set of genes demonstrates statistically significant, consistent differences between two biological states, including phenotypes (33). In the present study, the original mRNA sequencing data of BC were downloaded from TCGA and the samples were sorted in terms of ZWINT expression levels. A hundred samples were divided into high or low categories (50 samples in each category) based on the ZWINT expression levels, in order to annotate phenotype and the 'Hallmarks' gene set from the Molecular Signatures 
Table I. ZW10 interacting kinetochore protein expression in different subtypes of breast carcinoma.

\begin{tabular}{|c|c|c|c|c|c|c|}
\hline Subtype & Cancer & Normal & P-value & Fold change & Rank (\%) & Source of raw data (ref) \\
\hline Invasive Breast Carcinoma & 76 & 61 & $3.19 \times 10^{-35}$ & 5.133 & 1 & \\
\hline Invasive Lobular Breast Carcinoma & 36 & 61 & $1.47 \times 10^{-18}$ & 4.373 & 1 & TCGA (14) \\
\hline Invasive Ductal Breast Carcinoma & 389 & 61 & $2.73 \times 10^{-44}$ & 5.989 & 1 & \\
\hline Invasive Ductal Breast Carcinoma & 1556 & 144 & $3.04 \times 10^{-121}$ & 2.809 & 1 & \\
\hline Invasive Breast Carcinoma & 21 & 144 & $1.09 \times 10^{-8}$ & 2.313 & 1 & \\
\hline Invasive Lobular Breast Carcinoma & 148 & 144 & $3.80 \times 10^{-49}$ & 2.253 & 1 & \\
\hline $\begin{array}{l}\text { Invasive Ductal and Invasive Lobular } \\
\text { Breast Carcinoma }\end{array}$ & 90 & 144 & $4.24 \times 10^{-35}$ & 2.564 & 1 & Curtis et al (15) \\
\hline Medullary Breast Carcinoma & 32 & 144 & $5.66 \times 10^{-15}$ & 2.789 & 1 & \\
\hline Mucinous Breast Carcinoma & 46 & 144 & $3.96 \times 10^{-17}$ & 2.208 & 2 & \\
\hline Breast Carcinoma & 14 & 144 & $8.10 \times 10^{-6}$ & 2.547 & 3 & \\
\hline Tubular Breast Carcinoma & 67 & 144 & $2.45 \times 10^{-23}$ & 2.087 & 3 & \\
\hline Invasive Ductal Breast Carcinoma & 9 & 14 & $6.50 \times 10^{-5}$ & 3.553 & 2 & Ma et al (16) \\
\hline Ductal Breast Carcinoma In Situ & 9 & 14 & $3.74 \times 10^{-5}$ & 3.787 & 2 & \\
\hline Ductal Breast Carcinoma & 40 & 7 & $9.56 \times 10^{-6}$ & 7.593 & 6 & Richardson et al (17) \\
\hline
\end{tabular}
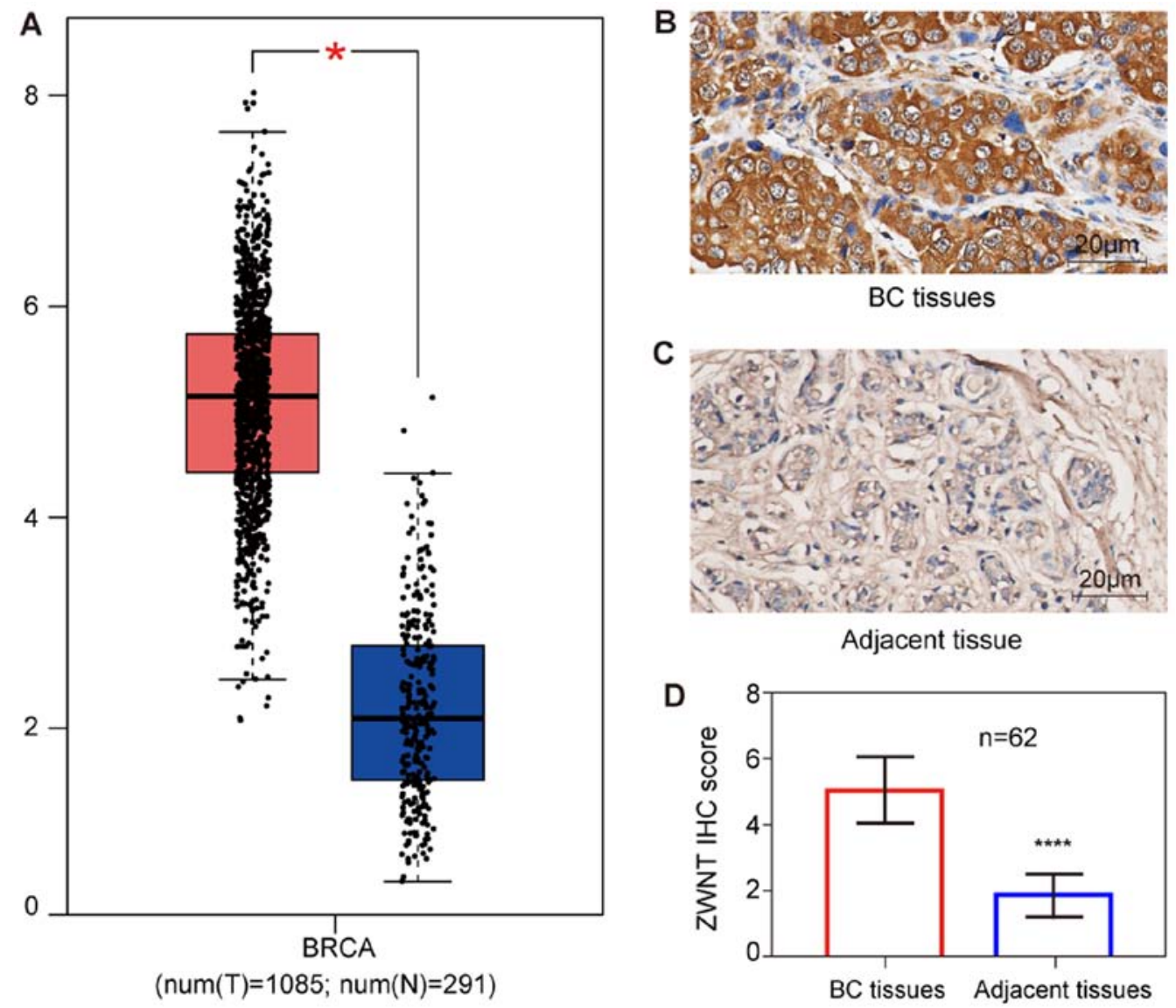

Figure 1. ZWINT is upregulated in BC. (A) mRNA expression of ZWINT in BC and normal breast tissues (GEPIA database). The red square and letter T correspond to tumor tissues, while the blue square and letter N correspond to normal tissues. (B and C) Protein expression of ZWINT was analyzed by IHC $(\mathrm{n}=62)$. (D) Total ZWINT IHC scores are displayed in a histogram. ${ }^{*} \mathrm{P}<0.05$ and ${ }^{* * * *} \mathrm{P}<0.0001$. BC, breast cancer; IHC, immunohistochemistry; ZWINT, ZW10 interacting kinetochore protein.

Database (MSigDB h.all.v6.2.symbols.gmt) was used for enrichment analysis. False discovery rate $<0.25$ and nominal $\mathrm{P}$-value $<0.05$ were set as cut-off criteria.
Co-expression and correlation analysis. The "coexpression analysis' module of Oncomine database was used to investigate the co-expressed genes of ZWINT in BC. The feature of 'gene 
A

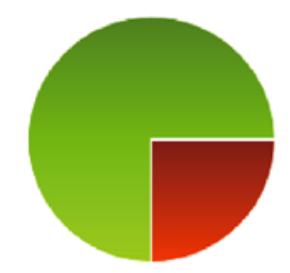

\begin{tabular}{ll} 
Colour Mutation type & $\begin{array}{l}\text { Number of } \\
\text { samples (\%) }\end{array}$ \\
\hline Nonsense substitution & $0(0.00 \%)$ \\
Missense substitution & $3(75.00 \%)$ \\
\hline Synonymous substitution $1(25.00 \%)$ \\
Inframe insertion & $0(0.00 \%)$ \\
Frameshift insertion & $0(0.00 \%)$ \\
Inframe deletion & $0(0.00 \%)$ \\
Frameshift deletion & $0(0.00 \%)$ \\
Complex mutation & $0(0.00 \%)$ \\
Other & $0(0.00 \%)$ \\
Total unique samples & 4
\end{tabular}

C

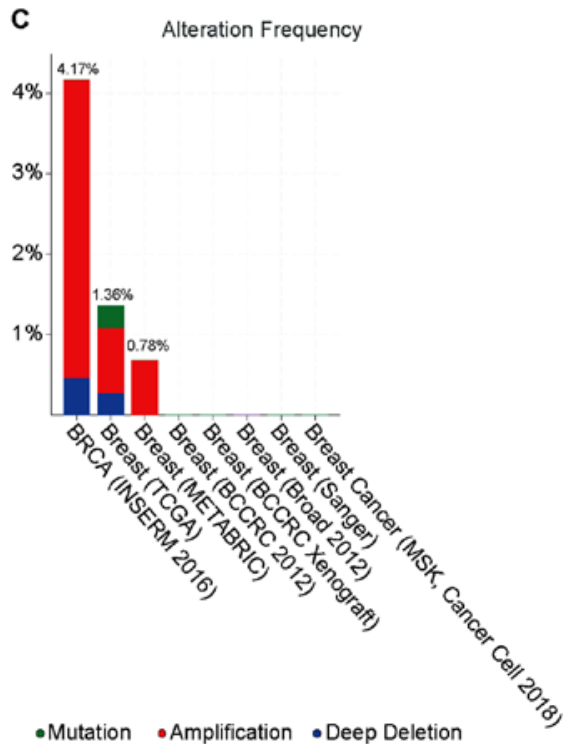

B

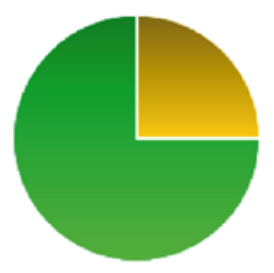

\begin{tabular}{cl}
$\begin{array}{c}\text { Colour } \\
\text { Mutation } \\
\text { type }\end{array}$ & $\begin{array}{l}\text { Number of } \\
\text { samples (\%) }\end{array}$ \\
\hline $\mathrm{A}>\mathrm{C}$ & $0(0.00 \%)$ \\
$\mathrm{A}>\mathrm{G}$ & $0(0.00 \%)$ \\
$\mathrm{A}>\mathrm{T}$ & $0(0.00 \%)$ \\
$\mathrm{C}>\mathrm{A}$ & $1(25.00 \%)$ \\
\hline $\mathrm{C}>\mathrm{T}$ & $0(0.00 \%)$ \\
$\mathrm{C}>\mathrm{G}$ & $0(0.00 \%)$ \\
$\mathrm{G}>\mathrm{A}$ & $3(75.00 \%)$ \\
$\mathrm{G}>\mathrm{C}$ & $0(0.00 \%)$ \\
$\mathrm{G}>\mathrm{T}$ & $0(0.00 \%)$ \\
$\mathrm{T}>\mathrm{A}$ & $0(0.00 \%)$ \\
$\mathrm{T}>\mathrm{C}$ & $0(0.00 \%)$ \\
$\mathrm{T}>\mathrm{G}$ & $0(0.00 \%)$ \\
$\mathrm{T}$ &
\end{tabular}

Total unique samples 4

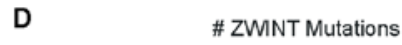

5

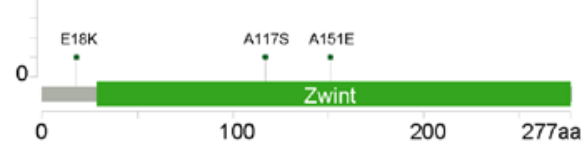

Figure 2.ZWINT mutations in BC. Pie charts demonstrating the (A) distribution and (B) percentage of the substitution types of ZWINT in BC based on results from the COSMIC database. (C) Genomic alteration frequency and (D) the somatic mutation types of ZWINT in BC was analyzed by searching the cBio Cancer Genomics Portal database. BC, breast cancer; ZWINT, ZW10 interacting kinetochore protein.

correlation analysis' of the cBioPortal and bc-GenExMiner was used to verify the co-expression of ZWINT and CDK1 in $\mathrm{BC}$, and linear (Pearson) and/or nonparametric (Spearman) correlation coefficients were calculated to assess the correlation intensity between these two genes. $\mathrm{P}<0.05$ was considered to be statistically significant.

Statistical analysis. IHC data were analyzed using SPSS software (version 21.0; IBM Corp.). A Wilcoxon matched-pairs signed rank test was conducted to compare BC tissues and adjacent normal tissues, and data are presented as the median \pm interquartile range. Fisher's exact test was used to analyze the association between ZWINT expression and clinicopathological characteristics. Moreover, data from the bc-GenExMiner database were used to analyze the mRNA expression of ZWINT in terms of clinicopathological characteristics with Welch's test and the Dunnett-Tukey-Kramer's test. The MRFS and MR of BC patients were estimated by the univariate Cox regression. $\mathrm{P}<0.05$ was considered to indicate a statistically significant difference. 
A

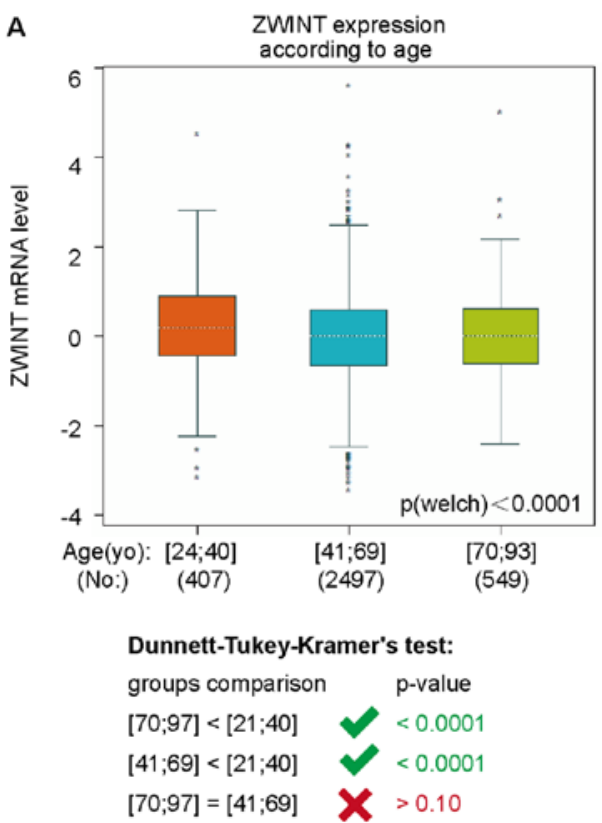

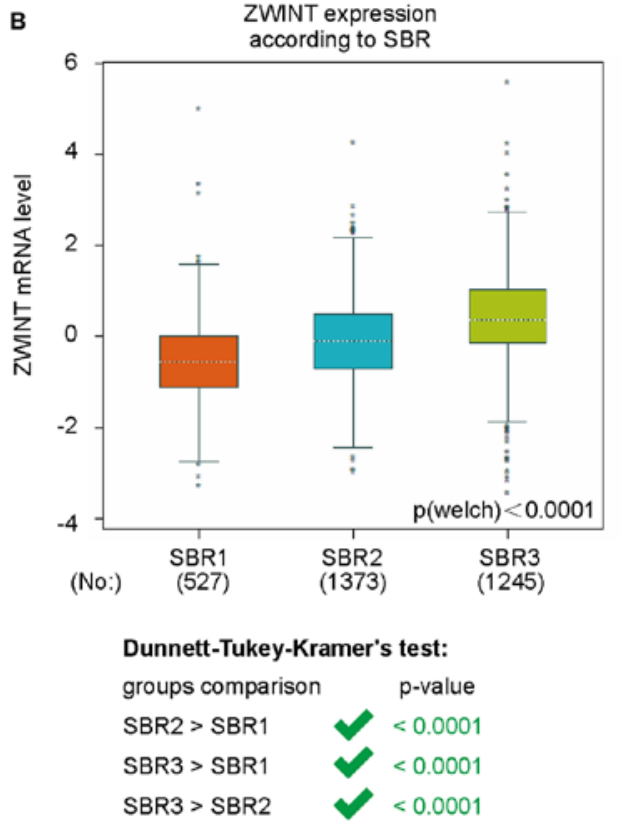

Figure 3. Relationship between ZWINT expression and (A) age and (B) SBR grading in patients with breast cancer. The differences among groups were evaluated using Welch's test to generate a P-value, in combination with the Dunnett-Tukey-Kramer's test. SBR, Scarff Bloom and Richardson; ZWINT, ZW10 interacting kinetochore protein.

\section{Results}

ZWINT expression in human BC. The mRNA expression profile of ZWINT in BC was studied by searching GEPIA and the Oncomine database. Elevated ZWINT expression was identified in $\mathrm{BC}$ tissues compared with normal tissues (Fig. 1A). Furthermore, the results demonstrated that ZWINT mRNA was significantly overexpressed in mucinous, medullary, invasive lobular and invasive ductal breast carcinoma compared with the normal breast tissues (Table I). In addition, IHC analysis confirmed that ZWINT expression was higher in $\mathrm{BC}$ tissues compared with adjacent normal breast tissues (Fig. 1B-D).

ZWINT mutations in human BC. COSMIC database analysis identified two types of ZWINT mutations in BC, missense and synonymous substitutions (Fig. 2A). For substitution mutations, the data revealed that $\mathrm{C}>\mathrm{A}$ and $\mathrm{G}>\mathrm{A}$ mutations accounted for 25 and $75 \%$ of the ZWINT coding strand, respectively (Fig. 2B). cBioPortal was applied to assess the genomic alteration frequency of ZWINT in BC and the results revealed that ZWINT genomic alteration exceeded 5\%, including amplification, mutation and deep deletion (Fig. 2C). A total of three locations of ZWINT mutation, including E18K, A117S and A151E, were found in cBioPortal database (Fig. 2D).

Association between ZWINT expression and different clinicopathological indicators. In bc-GenExMiner, the mRNA expression of ZWINT among groups of patients with different clinicopathological parameters was assessed using Welch's test followed by the Dunnett-Tukey-Kramer's test. The mRNA expression levels of ZWINT were significantly increased in patients aged 24-40, compared with those aged 41-69
Table II. Clinicopathological characteristics and the mRNA expression levels of ZWINT in patients with BC according to the bc-GenExMiner analysis. ${ }^{\mathrm{a}}$

\begin{tabular}{lccc}
\hline Variables & Number & mRNA expression & P-value \\
\hline $\begin{array}{l}\text { Nodal status } \\
\text { Negative }\end{array}$ & 2426 & - & 0.7048 \\
Positive & 1480 & - & \\
ER (IHC) & & & $<0.0001$ \\
$\quad$ Negative & 1388 & Increased & \\
Positive & 3675 & - & \\
PR (IHC) & & & $<0.0001$ \\
$\quad$ Negative & 804 & Increased & \\
Positive & 1249 & - & 0.0216 \\
HER2 (IHC) & & & \\
$\quad$ Negative & 1409 & - & \\
Positive & 201 & Increased & \\
Triple-negative status & & & $<0.0001$ \\
$\quad$ No & 3831 & - & \\
Yes & 374 & Increased & \\
Basal-like status & & & $<0.0001$ \\
$\quad$ None-basal-like & 3904 & - & \\
Basal-like & 1048 & Increased & \\
\hline
\end{tabular}

aWINT mRNA expression data are derived from bc-GenExMiner and the P-value is from Welch's test, which was followed by the Dunnett-Tukey-Kramer's test. bc-GenExMiner, Breast Cancer Gene-Expression Miner; ER, estrogen receptor; HER2, human epidermal growth factor receptor 2; IHC, immunohistochemistry; N, nodal status; PR, progesterone receptor; ZWINT, ZW10 interacting kinetochore protein. 
A

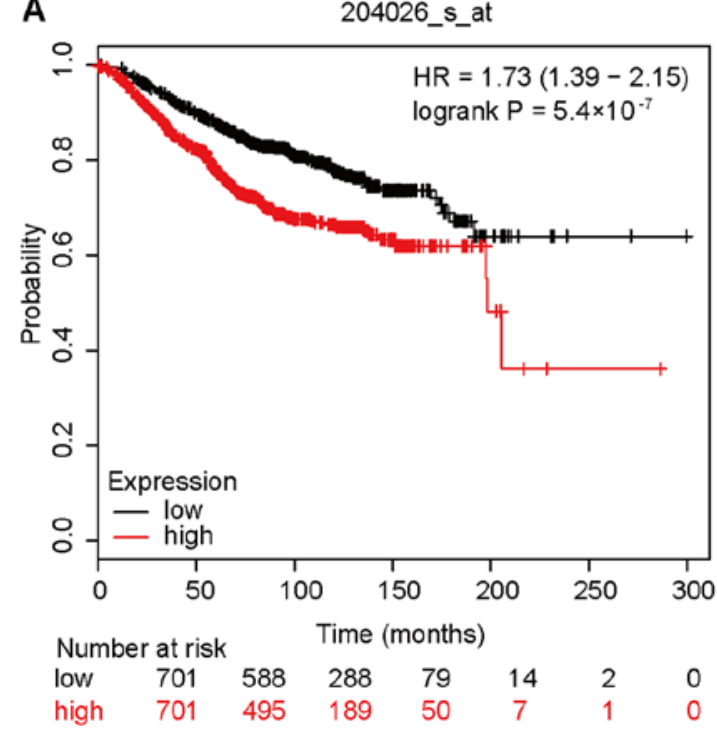

B

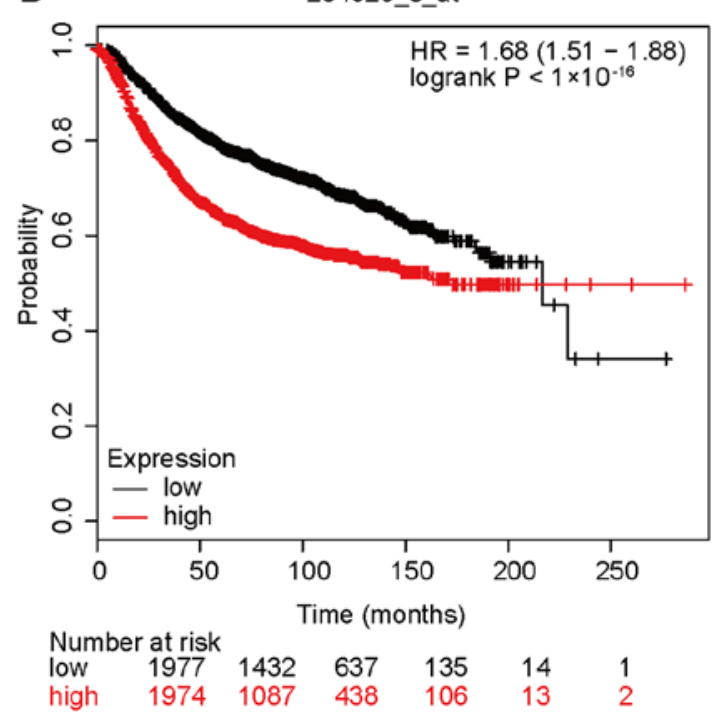

Figure 4. Relationship between the expression of ZWINT and overall and relapse-free survival of patients with BC. (A) Overall and (B) relapse-free survival of the patients with BC were computed using the Kaplan-Meier Plotter web tool. BC, breast cancer; CI, confidence interval; HR, hazard ratio; ZWINT, ZW10 interacting kinetochore protein.

Table III. ZWINT expression in subgroups as detected by immunohistochemistry.

\section{ZWINT expression}

Variables

Age (years)

$\leq 40$

$>40$

Nodal status

Negative

Positive

ER

Negative

Positive

PR

Negative
Positive

HER2

Negative
Positive

Triple-negative status

No

Yes
Number (n=62) Low High P-value

0.0063

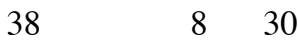

$24 \quad 14 \quad 10$

0.2884

$37 \quad 11 \quad 26$

25

$11 \quad 14$

0.2891

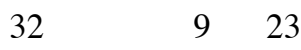

$\begin{array}{lll}30 & 13 & 17\end{array}$

38

24

$\begin{array}{ll}7 & 31 \\ 15 & 9\end{array}$

159

0.0277

0.0008

$10 \quad 30$

$12 \quad 10$

0.0018

ER, estrogen receptor; HER2, human epidermal growth factor receptor 2; N, nodal status; PR, progesterone receptor; ZWINT, ZW10 interacting kinetochore protein.

$(\mathrm{P}<0.0001)$ and $70-93(\mathrm{P}<0.01)$. Nevertheless, no statistical difference was observed between patients aged 41-69 and aged
70-93 (P>0.1; Fig. 3A). Additionally, no significant differences were found between patients with positive nodal status and those with negative status $(\mathrm{P}=0.7048$; Table II). Furthermore, in terms of classical molecular types of $\mathrm{BC}$, patients with estrogen receptor $(\mathrm{ER})^{-}$or progesterone receptor $(\mathrm{PR})^{-}(\mathrm{P}<0.0001$ for both) and human epidermal growth factor receptor 2 (HER2) ${ }^{+}$ $(\mathrm{P}=0.0216)$ status had higher ZWINT expression levels than their respective opposite status (Table II). Triple-negative BC (TNBC), an aggressive type of $\mathrm{BC}$, has been identified to lack expression of PR, ER and HER2 (34). The expression of ZWINT was found to be significantly upregulated in patients with TNBC $(\mathrm{P}<0.0001$; Table II). Additionally, patients with basal-like features had significantly increased ZWINT expression compared with patients without basal-like traits $(\mathrm{P}<0.0001$; Table II). Moreover, in terms of Scarff Bloom and Richardson (SBR) grades, patients with a more advanced SBR grade exhibited higher ZWINT expression (SBR3 $>$ SBR1, $\mathrm{P}<0.0001$; $\mathrm{SBR} 2>\mathrm{SBR} 1, \mathrm{P}<0.0001$; $\mathrm{SBR} 3>\mathrm{SBR} 2, \mathrm{P}<0.0001$; Fig. 3B). In addition to these results, IHC indicated significant differences in the protein expression of ZWINT between various age groups, PR and HER2 expression groups, and TNBC status groups (all $\mathrm{P}<0.05$ ), whereas there was no statistically significant difference between groups with different node status or ER expression status (both $\mathrm{P}>0.05$; Table III).

ZWINT expression and the prognosis of patients with $B C$. According to Kaplan-Meier Plotter analysis, higher ZWINT expression was associated with a shorter OS (HR $=1.73 ; 95 \%$ $\left.\mathrm{CI}=1.39-2.15 ; \mathrm{P}=5.4 \times 10^{-7}\right)$ and a shorter RFS (HR=1.68; 95\% $\mathrm{CI}=1.51-1.88 ; \mathrm{P}<1 \times 10^{-16}$ ) (Fig. 4). Gene prognostic analysis was conducted with bc-GenExMiner, which involved the integration of the accessible annotated genomic resources in order to explore the association between ZWINT expression and metastatic relapse-free survival (MRFS). As presented in Fig. 5A, increased ZWINT expression levels were related to shorter MRFS (HR=1.66; 95\% CI=1.46-1.89; $\mathrm{P}<0.0001)$. Moreover, a 
Table IV. Association between ZW10 interacting kinetochore protein expression and predefined gene signatures, as determined by Gene Set Enrichment Analysis.

\begin{tabular}{lrcccc}
\hline Name & Size & ES & NES & NOM P-value & FDR q-value \\
\hline HALLMARK_MYC_TARGETS_V1 & 198 & 0.740607 & 2.01761 & 0 & 0.007663 \\
HALLMARK_DNA_REPAIR & 140 & 0.55583 & 2.001272 & 0 & 0.004239 \\
HALLMARK_MITOTIC_SPINDLE & 198 & 0.616344 & 1.98359 & 0 & 0.003048 \\
HALLMARK_MTORC1_SIGNALING & 196 & 0.63402 & 1.968746 & 0.001957 & 0.003571 \\
HALLMARK_MYC_TARGETS_V2 & 58 & 0.755216 & 1.92142 & 0.001965 & 0.005123 \\
HALLMARK_UNFOLDED_PROTEIN_RESPONSE & 108 & 0.492682 & 1.888622 & 0.009653 & 0.00677 \\
HALLMARK_SPERMATOGENESIS & 73 & 0.607111 & 1.791163 & 0.00813 & 0.015301 \\
HALLMARK_G2M_CHECKPOINT & 196 & 0.822451 & 1.774046 & 0 & 0.016042 \\
HALLMARK_E2F_TARGETS & 199 & 0.865591 & 1.763097 & 0 & 0.01676 \\
HALLMARK_OXIDATIVE_PHOSPHORYLATION & 198 & 0.550228 & 1.748484 & 0.052731 & 0.017751 \\
HALLMARK_GLYCOLYSIS & 181 & 0.430354 & 1.544676 & 0.040619 & 0.083129 \\
\hline
\end{tabular}

ES, enrichment score; FDR, false discovery rate; NES, normalized enrichment score; NOM, nominal.

A

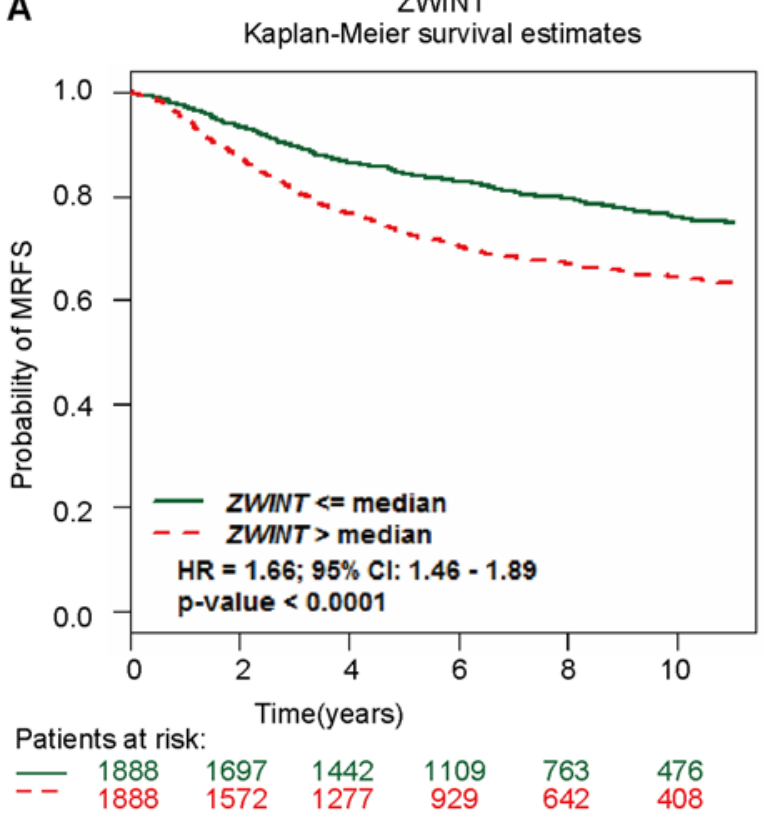

\section{B}

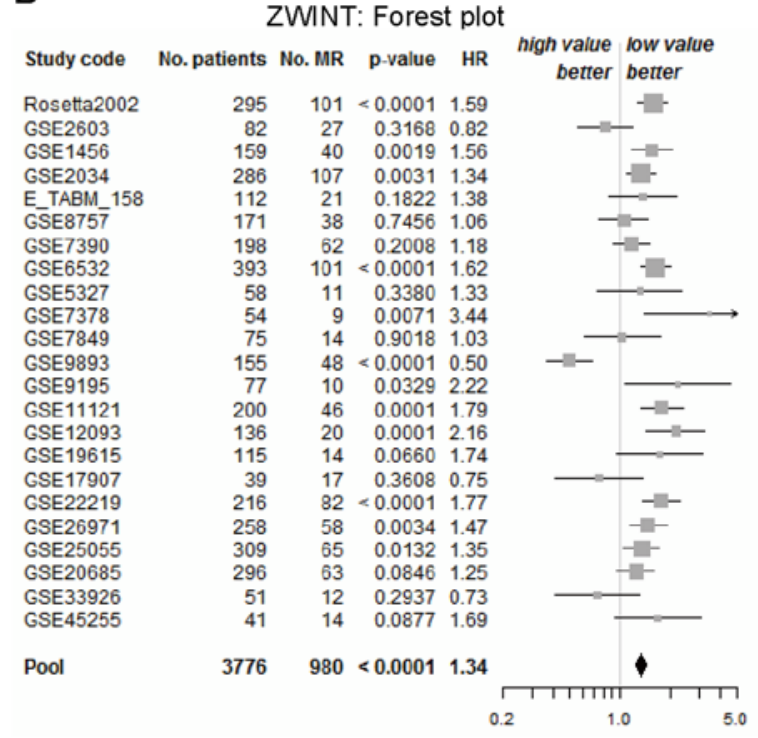

Figure 5. Association of ZWINT expression and the MRFS of patients with BC (Breast Cancer Gene-Expression Miner). (A) Relationship between ZWINT expression and MRFS of patients with BC was estimated by employing the Kaplan-Meier survival analysis. (B) Forest plots demonstrating the univariate Cox regression of ZWINT expression and the risk of MR. BC, breast cancer; MR, metastatic relapse; MRFS, metastatic relapse-free survival; ZWINT, ZW10 interacting kinetochore protein.

higher risk of metastatic relapse was observed in patients with elevated ZWINT expression $(\mathrm{HR}=1.34$; $95 \% \mathrm{CI}=1.26-1.43$; $\mathrm{P}<0.0001$; Fig. 5B).

Molecular mechanisms and co-expression of ZWINT in BC. Increased ZWINT expression was found to be related to worse prognosis in patients with BC. Nonetheless, the underlying molecular mechanisms remain to be explored. In order to evaluate whether the expression levels of ZWINT were related to known gene signatures, GSEA was performed with BC RNA-sequencing data from TCGA database. GSEA revealed that 11 hallmark pathways were upregulated in the high ZWINT expression group, indicating that ZWINT expression was positively associated with these pathways (Table IV). Most of these pathways are implicated in cellular metabolism, biosynthesis and cell damage repair processes, including Myc targets V1/2, DNA repair, mitotic spindle, G2M checkpoint and E2F targets (Fig. 6). In addition, co-expression analysis was performed using the Oncomine database to further study the regulation of ZWINT. In total, 124 co-expression genes were filtered out in a cohort of 289 patients with BC (Fig. 7A) (35). The gene with the greatest correlation score, cyclin-dependent kinase 1 (CDK1), is considered to serve an important role in the regulation of 
A Enrichment plot: HALLMARK_MYC_TARGETS_V1

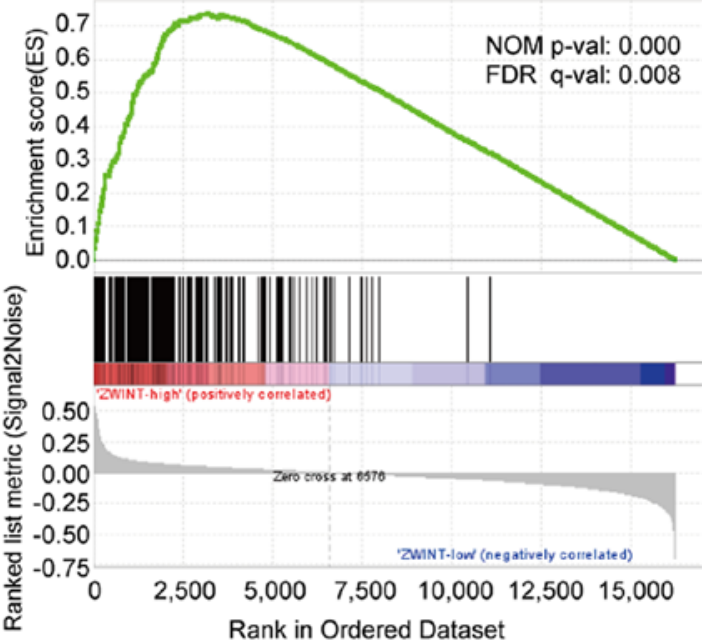

- Enrichment profile - Hits _ _ Ranking metric scores

C Enrichment plot: HALLMARK_DNA_REPAIR

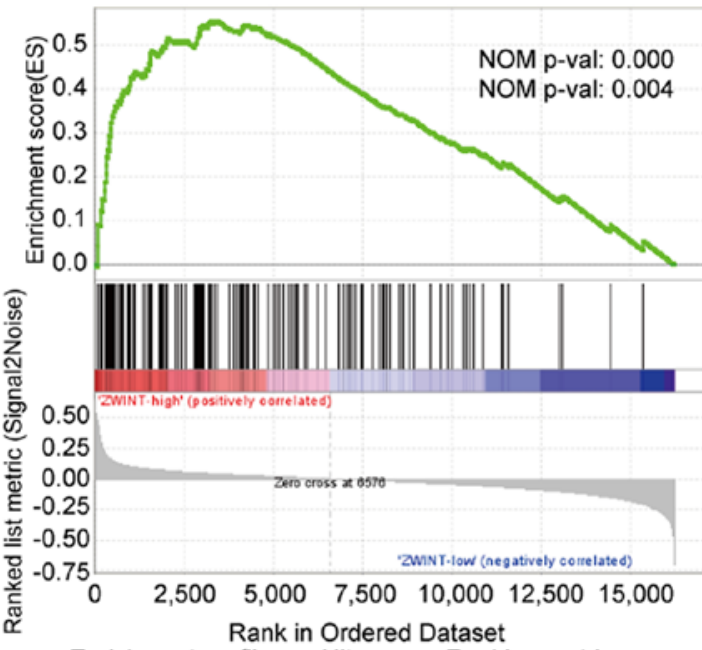

- Enrichment profile - Hits _ Ranking metric scores

E Enrichment plot: HALLMARK_G2M_CHECKPOINT

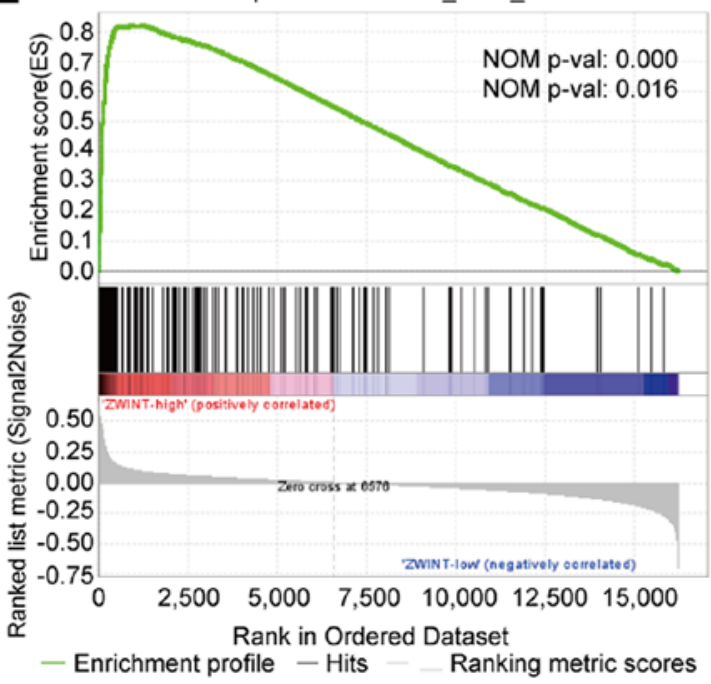

B

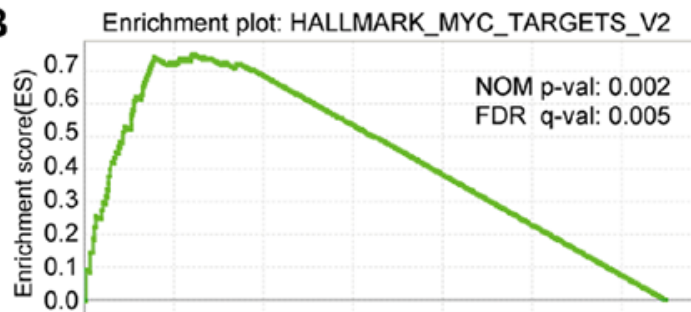

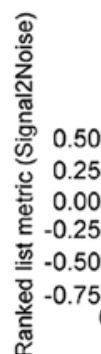

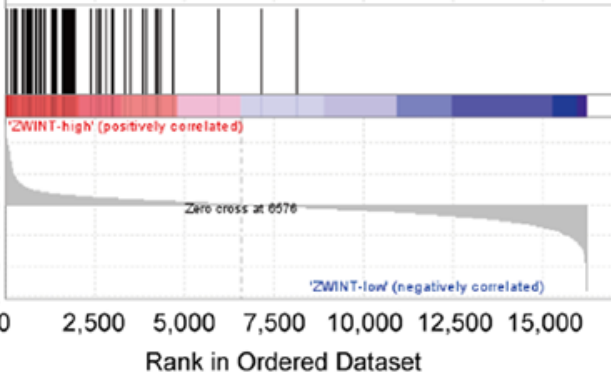

- Enrichment profile - Hits _ _ Ranking metric scores

D Enrichment plot: HALLMARK_MITOTIC_SPINDLE
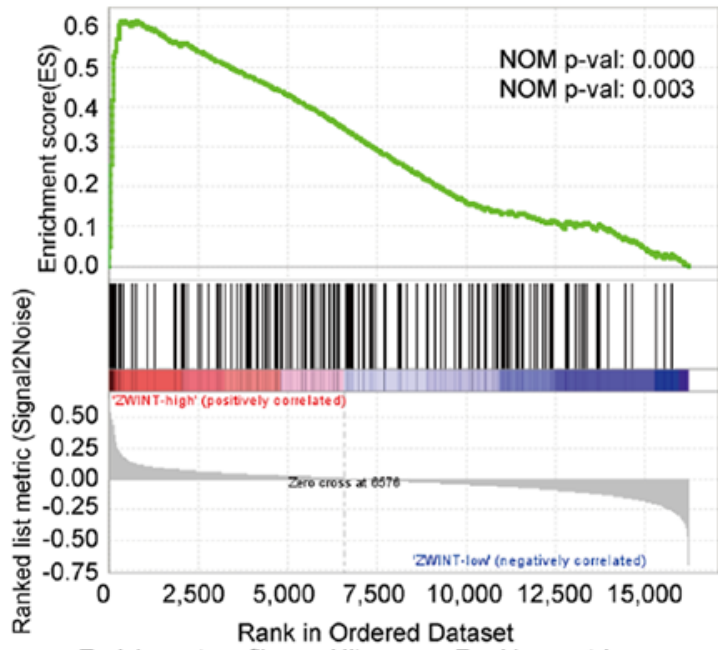

- Enrichment profile - Hits _ Ranking metric scores

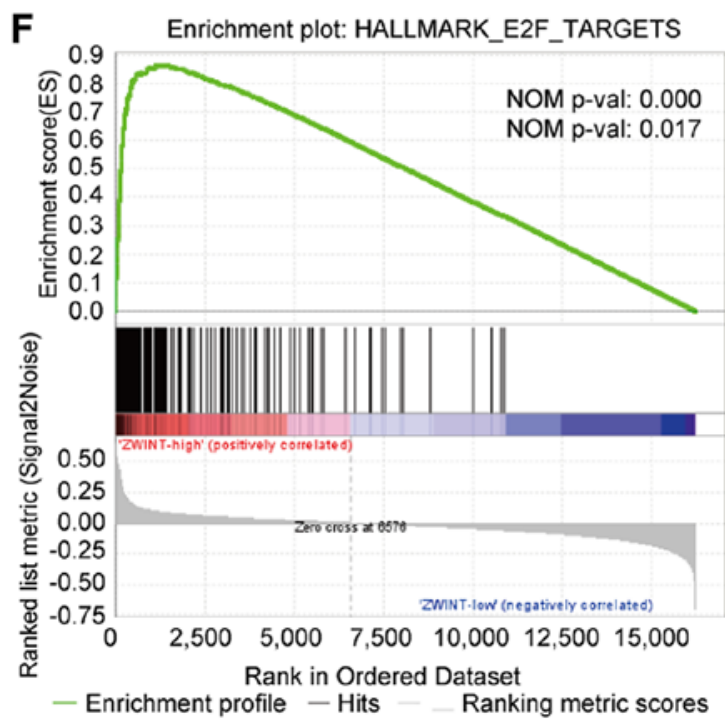

Figure 6. Association between ZW10 interacting kinetochore protein expression and predefined gene sets by Gene Set Enrichment Analysis in The Cancer Genome Atlas database. (A) MYC targets V1; (B) MYC targets V2; (C) DNA repair; (D) mitotic spindle; (E) G2M checkpoint; (F) E2F targets. ES, enrichment score; FDR, false discovery rate; NOM, nominal.

the cell cycle process and has been confirmed to be abnormally upregulated in several types of cancer by numerous studies (36-40). A positive correlation was confirmed between ZWINT and CDK1 mRNA expression in the METABRIC 
A
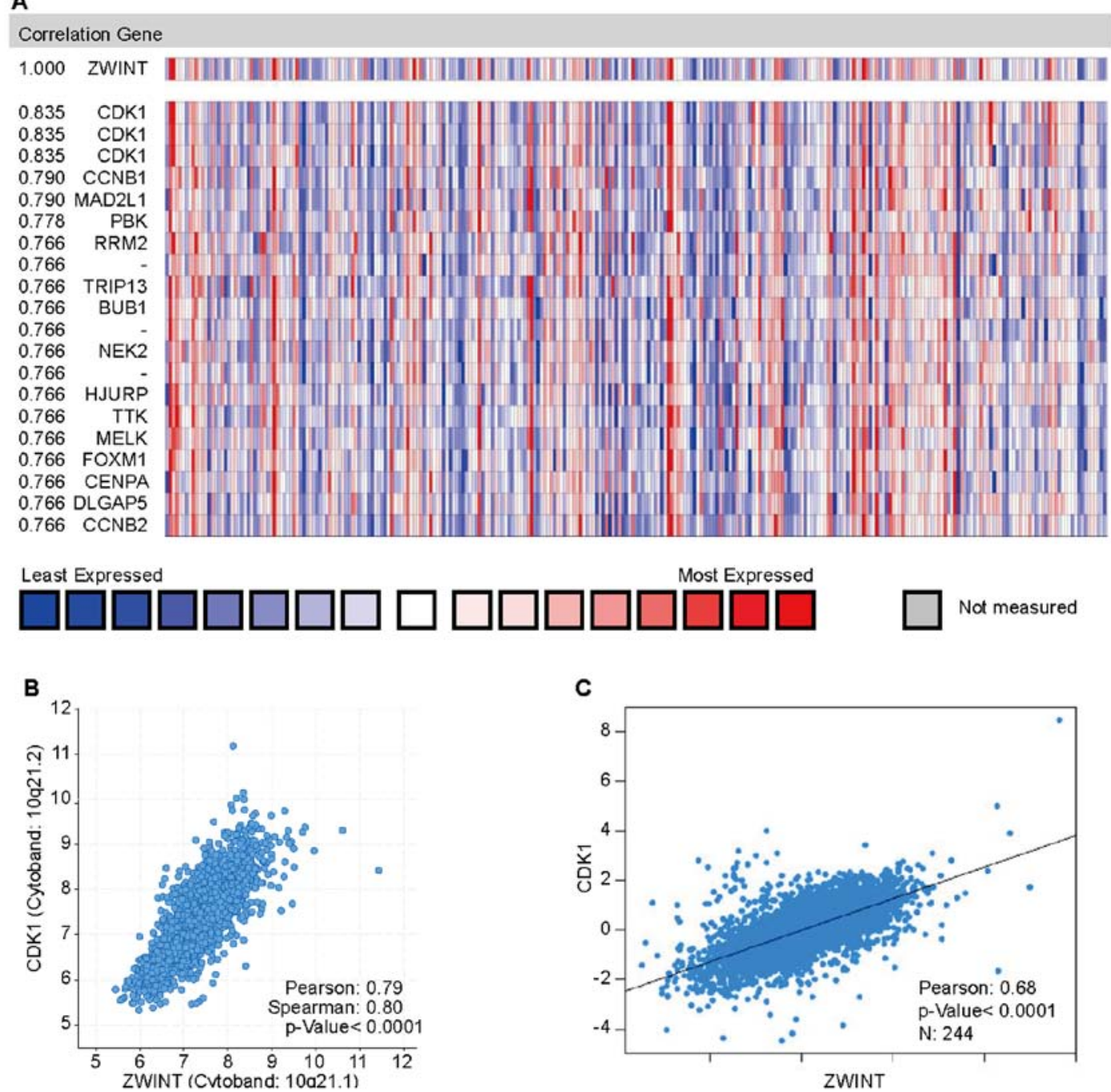

Figure 7. Co-expression analysis of ZWINT in BC. (A) Co-expression genes of ZWINT were assessed using the Oncomine database. Correlation between ZWINT and CDK1 mRNA expression in BC was analyzed using (B) cBio Cancer Genomics Portal and (C) Breast Cancer Gene-Expression Miner. BC, breast cancer; CDK1, cyclin-dependent kinase 1; ZWINT, ZW10 interacting kinetochore protein.

database by employing cBioPortal (Spearman's correlation $=0.80$; Pearson's correlation=0.79; Fig. 7B). Data mining in bc-GenExMiner further verified the positive correlation between ZWINT and CDK1 mRNA expression (Fig. 7C). These results indicated that ZWINT could be involved in biosynthesis, cell cycle and damage repair processes, and may be related to CDK1 signaling pathways.

\section{Discussion}

Previous studies have examined the expression and roles of ZWINT in multiple types of cancer $(7-9,11,12)$. Endo et al (10) demonstrated that the interaction of ZWINT with Terf/TRIM17 resulted in its degradation and the consequent regulation of cell proliferation in BC MCF-7 and 293-T cells. Miller et al (41) identified a total of 62 genes, including ZWINT, whose expression levels were markedly changed in BC after short-term therapy with letrozole, indicating that ZWINT was potentially involved in estrogen regulation. However, the expression profile of ZWINT and its effect on BC prognosis remain unexplored.
In the present study, the expression profile of ZWINT in BC was initially evaluated by IHC and GEPIA. Both the mRNA and protein expression levels of ZWINT were found to be elevated in BC tissues, suggesting that it may serve an oncogenic role in $\mathrm{BC}$. The Oncomine database search revealed that the transcriptional expression of ZWINT was significantly upregulated in mucinous, medullary, invasive lobular and invasive ductal breast carcinoma. Furthermore, increased ZWINT expression was found to be significantly associated with HER2 positivity, a basal-like subtype of breast carcinoma, TNBC and increased histological grades according to SBR grading. Moreover, significant associations were observed between increased ZWINT mRNA expression and negative expression of ER/PR as well as younger age of the patients. Previous studies have demonstrated that BC in young women (BCYW) has distinctive clinicopathological characteristics compared with BC in post-menopausal women $(42,43)$. Specifically, $\mathrm{BCYW}$ is often of a higher grade, is more aggressive, lacks endocrine receptor expression and has a higher proportion of HER $2^{+}$and triple-negative histology (44-46). The present 
study demonstrated that ZWINT mRNA expression was higher in BCYW than in BC in older patients, suggesting that ZWINT may serve an important role in the progression of $\mathrm{BC}$, particularly in BCYW. Furthermore, IHC detection revealed a close association between ZWINT expression and the age of patients, PR and HER 2 status, and TNBC in BC. Nevertheless, the results were partly in disagreement with the findings of the bc-GenExMiner. For instance, no association was found between ZWINT expression and ER status in the study cohort, which may be due to the relatively small sample size, and ethnic or geographical differences. Kaplan Meier-plotter analysis revealed that high ZWINT expression was related to unfavorable OS and RFS. Additionally, data mining with bc-GenExMiner demonstrated that high ZWINT expression was strongly associated with increased risk of metastatic relapse. These findings suggested that ZWINT may serve as a biomarker for the prognosis of $\mathrm{BC}$.

To explore the role of ZWINT in BC, GSEA was performed. This analysis demonstrated that higher expression of ZWINT was closely associated with cell cycle-related pathways, including Myc targets $\mathrm{V} 1 / 2$, DNA repair, mitotic spindle, G2M checkpoint and E2F targets. It is generally believed that aberrant cellular proliferation is a hallmark of malignancies and tumor cells tend to exhibit altered expression of genes that directly modulate their cell cycle (47). This process occurs either via mutations in the upstream signaling pathways or as a consequence of genetic impairments in genes encoding cell cycle-related proteins (48). As a proto-oncogene, Myc encodes a nuclear phosphoprotein and is involved in cell cycle progression, apoptosis and cellular transformation (49). Myc is rigorously controlled in normal cells, whereas it is aberrantly expressed in the majority of types of human cancer (50). Notably, the internal interaction between Myc and the E2F family of transcription factors in $\mathrm{BC}$ has been reported by several studies. For instance, Fujiwara et al (51) generated a hybrid mouse model and demonstrated that Myc-induced breast tumor latency was significantly decreased in E2F1 knockout mice and increased in E2F2 and E2F3 knockout mice. A follow-up study, however, revealed that lack of E2F1 or E2F3 significantly postponed tumor onset in both ErbB2- and Myc-triggered breast tumorigenesis, whereas lack of E2F2 promoted breast tumorigenesis induced by Myc overexpression (52). The present results demonstrated that in addition to recognized involvement in the mitotic spindle checkpoint, ZWINT may participate in the signaling pathways of Myc and E2F in BC. Nevertheless, given the complexity of the cell cycle, the precise role of ZWINT in $\mathrm{BC}$ could not be determined. To further investigate the molecular mechanism of ZWINT in BC, co-expression and correlation analyses were performed. It was demonstrated that ZWINT may be closely associated with the CDK1 signaling pathways in BC. Importantly, CDK1 has been observed to serve an essential role in tumor initiation and progression in different types of carcinomas $(40,53,54)$. Ablation of the CDK1 gene induced resistance to NRAS-G12V-induced tumorigenesis in liver cells (55). Moreover, CDK1 inhibition in combination with mitogen-activated protein kinase kinase inhibition synergistically increased the apoptotic rate of colorectal cancer cells and decreased clonogenic survival as compared with monotreatment (56). These results suggested that ZWINT may promote tumor formation and progression by modulating CDK1 expression in BC. Further studies are warranted to determine the relationship between ZWINT and CDK1 in BC.

In summary, the present study identified that ZWINT was commonly upregulated in $\mathrm{BC}$ and may aid prognostic prediction in patients with BC. ZWINT may serve as an independent prognostic biomarker for $\mathrm{BC}$; however, further research is required to substantiate the findings of the present study.

\section{Acknowledgments}

Not applicable.

\section{Funding}

This project was supported by the Hubei Provincial Natural Science Foundation of China (grant no. 2015000250) and the Clinical Research Physician Program of Tongji Medical College, HUST (grant no. 2017zqnlxr01).

\section{Availability of data and materials}

All data generated or analyzed during the present study are included in this published article.

\section{Authors' contributions}

HL was completed the bioinformatic research and was a major contributor of manuscript preparation. WZ designed the project and made the study plan. YD was responsible for the analysis of the clinical characteristics of breast cancer specimens. GW and MD performed the immunohistochemistry and analyzed the results. ZY and XL contributed to the writing and revision of the manuscript, and provided valuable input on the design of the experiment and the interpretation of the results. All authors read and approved the final version of the manuscript.

\section{Ethics approval and consent to participate}

The experimental protocol of the present study was approved by the Ethics Committee of Tongji Hospital. Written informed consent was obtained from all patients.

\section{Patient consent for publication}

The experimental protocol of this study was approved by the Ethics Committee of Tongji Hospital, Tongji Medical College of Huazhong University of Science and Technology. All patients provided signed informed consent.

\section{Competing interests}

The authors declare that they have no competing interests.

\section{References}

1. Bray F, Ferlay J, Soerjomataram I, Siegel RL, Torre LA and Jemal A: Global cancer statistics 2018: GLOBOCAN estimates of incidence and mortality worldwide for 36 cancers in 185 countries. CA Cancer J Clin 68: 394-424, 2018. 
2. Greenlee H, DuPont-Reyes MJ, Balneaves LG, Carlson LE, Cohen MR, Deng G, Johnson JA, Mumber M, Seely D, Zick SM, et al: Clinical practice guidelines on the evidence-based use of integrative therapies during and after breast cancer treatment. CA Cancer J Clin 67: 194-232, 2017.

3. Runowicz CD, Leach CR, Henry NL, Henry KS, Mackey HT, Cowens-Alvarado RL, Cannady RS, Pratt-Chapman ML, Edge SB, Jacobs LA, et al: American cancer society/American society of clinical oncology breast cancer survivorship care guideline. J Clin Oncol 34: 611-635, 2016.

4. Starr DA, Saffery R, Li Z, Simpson AE, Choo KH, Yen TJ and Goldberg ML: HZwint-1, a novel human kinetochore component that interacts with HZW10. J Cell Sci 113: 1939-1950, 2000.

5. Vos LJ, Famulski JK and Chan GK: hZwint-1 bridges the inner and outer kinetochore: Identification of the kinetochore localization domain and the hZw10-interaction domain. Biochem J 436: 157-168, 2011.

6. Kops GJ, Kim Y, Weaver BA, Mao Y, McLeod I, Yates JR III, Tagaya M and Cleveland DW: ZW10 links mitotic checkpoint signaling to the structural kinetochore. J Cell Biol 169: 49-60, 2005

7. Tang J, He D, Yang P, He J and Zhang Y: Genome-wide expression profiling of glioblastoma using a large combined cohort. Sci Rep 8: 15104, 2018.

8. Xu Z, Zhou Y, Cao Y, Dinh TL, Wan J and Zhao M: Identification of candidate biomarkers and analysis of prognostic values in ovarian cancer by integrated bioinformatics analysis. Med Oncol 33: 130, 2016

9. Ying $\mathrm{H}, \mathrm{Xu} \mathrm{Z}$, Chen $\mathrm{M}$, Zhou S, Liang $\mathrm{X}$ and Cai $\mathrm{X}$ : Overexpression of Zwint predicts poor prognosis and promotes the proliferation of hepatocellular carcinoma by regulating cell-cycle-related proteins. Onco Targets Ther 11: 689-702, 2018

10. Endo H,Ikeda K, Urano T, Horie-Inoue K and Inoue S: Terf/TRIM17 stimulates degradation of kinetochore protein ZWINT and regulates cell proliferation. J Biochem 151: 139-144, 2012.

11. Pérez de Castro I, de Cárcer G and Malumbres M: A census of mitotic cancer genes: New insights into tumor cell biology and cancer therapy. Carcinogenesis 28: 899-912, 2007.

12. Bieniek J, Childress C, Swatski MD and Yang W: COX-2 inhibitors arrest prostate cancer cell cycle progression by down-regulation of kinetochore/centromere proteins. Prostate 74: 999-1011, 2014

13. Tang Z, Li C, Kang B, Gao G, Li C and Zhang Z: GEPIA: A web server for cancer and normal gene expression profiling and interactive analyses. Nucleic Acids Res 45: W98-W102, 2017.

14. Cancer Genome Atlas Network: Comprehensive molecular portraits of human breast tumours. Nature 490: 61-70, 2012.

15. Curtis C, Shah SP, Chin SF, Turashvili G, Rueda OM, Dunning MJ, Speed D, Lynch AG, Samarajiwa S, Yuan Y, et al: The genomic and transcriptomic architecture of 2,000 breast tumours reveals novel subgroups. Nature 486: 346-352, 2012.

16. Ma XJ, Dahiya S, Richardson E, Erlander M and Sgroi DC: Gene expression profiling of the tumor microenvironment during breast cancer progression. Breast Cancer Res 11: R7, 2009.

17. Richardson AL, Wang ZC, De Nicolo A, Lu X, Brown M, Miron A, Liao X, Iglehart JD, Livingston DM and Ganesan S: $\mathrm{X}$ chromosomal abnormalities in basal-like human breast cancer. Cancer Cell 9: 121-132, 2006.

18. Jézéquel P, Campone M, Gouraud W, Guérin-Charbonnel C, Leux C, Ricolleau $G$ and Campion L: bc-GenExMiner: An easy-to-use online platform for gene prognostic analyses in breast cancer. Breast Cancer Res Treat 131: 765-775, 2012.

19. Jézéquel P, Frénel JS, Campion L, Guérin-Charbonnel C, Gouraud W, Ricolleau G and Campone M: bc-GenExMiner 3.0: New mining module computes breast cancer gene expression correlation analyses. Database (Oxford) 2013: bas060, 2013.

20. Györffy B, Lanczky A, Eklund AC, Denkert C, Budczies J, Li Q and Szallasi Z: An online survival analysis tool to rapidly assess the effect of 22,277 genes on breast cancer prognosis using microarray data of 1,809 patients. Breast Cancer Res Treat 123: 725-731, 2010.

21. Forbes SA, Beare D, Bindal N, Bamford S, Ward S, Cole CG, Jia M Kok C, Boutselakis H, De T, et al: COSMIC: High-resolution cancer genetics using the catalogue of somatic mutations in cancer. Curr Protoc Hum Genet 91: 10.11.1-10.11.37, 2016.

22. Forbes SA, Beare D, Boutselakis H, Bamford S, Bindal N, Tate J, Cole CG, Ward S, Dawson E, Ponting L, et al: COSMIC: Somatic cancer genetics at high-resolution. Nucleic Acids Res 45. D777-D783, 2017.

23. Cerami E, Gao J, Dogrusoz U, Gross BE, Sumer SO, Aksoy BA, Jacobsen A, Byrne CJ, Heuer ML, Larsson E, et al: The cBio cancer genomics portal: An open platform for exploring multidimensional cancer genomics data. Cancer Discov 2: 401-404, 2012.
24. Gao J, Aksoy BA, Dogrusoz U, Dresdner G, Gross B, Sumer SO, Sun Y, Jacobsen A, Sinha R, Larsson E, et al: Integrative analysis of complex cancer genomics and clinical profiles using the cBioPortal. Sci Signal 6: pl1, 2013.

25. Razavi P, Chang MT, Xu G, Bandlamudi C, Ross DS, Vasan N, Cai Y, Bielski CM, Donoghue MTA, Jonsson P, et al: The genomic landscape of endocrine-resistant advanced breast cancers. Cancer Cell 34: 427.e6-438.e6, 2018.

26. Pereira B, Chin SF, Rueda OM, Vollan HK, Provenzano E, Bardwell HA, Pugh M, Jones L, Russell R, Sammut SJ, et al: The somatic mutation profiles of 2,433 breast cancers refines their genomic and transcriptomic landscapes. Nat Commun 7: 11479, 2016.

27. Shah SP, Roth A, Goya R, Oloumi A, Ha G, Zhao Y, Turashvili G, Ding J, Tse K, Haffari G, et al: The clonal and mutational evolution spectrum of primary triple-negative breast cancers. Nature 486: 395-399, 2012.

28. Banerji S, Cibulskis K, Rangel-Escareno C, Brown KK, Carter SL, Frederick AM, Lawrence MS, Sivachenko AY Sougnez C, Zou L, et al: Sequence analysis of mutations and translocations across breast cancer subtypes. Nature 486: 405-409, 2012

29. Stephens PJ, Tarpey PS, Davies H, Van Loo P, Greenman C, Wedge DC, Nik-Zainal S, Martin S, Varela I, Bignell GR, et al: The landscape of cancer genes and mutational processes in breast cancer. Nature 486: 400-404, 2012.

30. Ciriello G, Gatza ML, Beck AH, Wilkerson MD, Rhie SK, Pastore A, Zhang H, McLellan M, Yau C, Kandoth C, et al: Comprehensive molecular portraits of invasive lobular breast cancer. Cell 163: 506-519, 2015.

31. Eirew P, Steif A, Khattra J, Ha G, Yap D, Farahani H, Gelmon K, Chia S, Mar C, Wan A, et al: Dynamics of genomic clones in breast cancer patient xenografts at single-cell resolution. Nature 518: 422-426, 2015.

32. Lefebvre C, Bachelot T, Filleron T, Pedrero M, Campone M, Soria JC, Massard C, Lévy C, Arnedos M, Lacroix-Triki M, et al: Mutational profile of metastatic breast cancers: A retrospective analysis. PLoS Med 13: e1002201, 2016.

33. Subramanian A, Tamayo P, Mootha VK, Mukherjee S, Ebert BL, Gillette MA, Paulovich A, Pomeroy SL, Golub TR, Lander ES and Mesirov JP: Gene set enrichment analysis: A knowledge-based approach for interpreting genome-wide expression profiles. Proc Natl Acad Sci USA 102: 15545-15550, 2005.

34. Foulkes WD, Smith IE and Reis-Filho JS: Triple-negative breast cancer. N Engl J Med 363: 1938-1948, 2010.

35. Ivshina AV, George J, Senko O, Mow B, Putti TC, Smeds J, Lindahl T, Pawitan Y, Hall P, Nordgren H, et al: Genetic reclassification of histologic grade delineates new clinical subtypes of breast cancer. Cancer Res 66: 10292-10301, 2006.

36. Malumbres M: Cyclin-dependent kinases. Genome Biol 15: 122 , 2014.

37. Ravindran Menon D, Luo Y, Arcaroli JJ, Liu S, Krishnan Kutty LN, Osborne DG, Li Y, Samson JM, Bagby S, Tan AC, et al: CDK1 interacts with Sox2 and promotes tumor initiation in human melanoma. Cancer Res 78: 6561-6574, 2018

38. Wei D, Parsels LA, Karnak D, Davis MA, Parsels JD, Marsh AC, Zhao L, Maybaum J, Lawrence TS, Sun Y and Morgan MA: Inhibition of protein phosphatase $2 \mathrm{~A}$ radiosensitizes pancreatic cancers by modulating $\mathrm{CDC} 25 \mathrm{C} / \mathrm{CDK} 1$ and homologous recombination repair. Clin Cancer Res 19: 4422-4432, 2013.

39. Whalley HJ, Porter AP, Diamantopoulou Z, White GR, Castañeda-Saucedo E and Malliri A: Cdk1 phosphorylates the Rac activator Tiam1 to activate centrosomal Pak and promote mitotic spindle formation. Nat Commun 6: 7437, 2015

40. Wu CX, Wang XQ, Chok SH, Man K, Tsang SHY, Chan ACY,

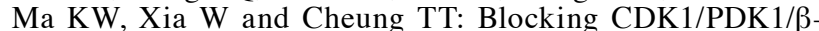
Catenin signaling by CDK1 inhibitor RO3306 increased the efficacy of sorafenib treatment by targeting cancer stem cells in a preclinical model of hepatocellular carcinoma. Theranostics 8 : 3737-3750, 2018.

41. Miller WR, Larionov AA, Renshaw L, Anderson TJ, White S, Murray J, Murray E, Hampton G, Walker JR, Ho S, et al: Changes in breast cancer transcriptional profiles after treatment with the aromatase inhibitor, letrozole. Pharmacogenet Genomics 17: 813-826, 2007

42. Cancello G, Maisonneuve P, Rotmensz N, Viale G, Mastropasqua MG, Pruneri G, Veronesi P, Torrisi R, Montagna E, Luini A, et al: Prognosis and adjuvant treatment effects in selected breast cancer subtypes of very young women $(<35$ years $)$ with operable breast cancer. Ann Oncol 21: 1974-1981, 2010. 
43. Narod SA: Breast cancer in young women. Nat Rev Clin Oncol 9: 460-470, 2012

44. Azim HA Jr, Michiels S, Bedard PL, Singhal SK, Criscitiello C, Ignatiadis M, Haibe-Kains B, Piccart MJ, Sotiriou C and Loi S: Elucidating prognosis and biology of breast cancer arising in young women using gene expression profiling. Clin Cancer Res 18: 1341-1351, 2012.

45. Han W and Kang SY; Korean Breast Cancer Society: Relationship between age at diagnosis and outcome of premenopausal breast cancer: Age less than 35 years is a reasonable cut-off for defining young age-onset breast cancer. Breast Cancer Res Treat 119: 193-200, 2010.

46. Keegan TH, DeRouen MC, Press DJ, Kurian AW and Clarke CA: Occurrence of breast cancer subtypes in adolescent and young adult women. Breast Cancer Res 14: R55, 2012.

47. Sherr CJ: Cancer cell cycles. Science 274: 1672-1677, 1996.

48. Otto T and Sicinski P: Cell cycle proteins as promising targets in cancer therapy. Nat Rev Cancer 17: 93-115, 2017.

49. Bretones G, Delgado MD and León J: Myc and cell cycle control. Biochim Biophys Acta 1849: 506-516, 2015.

50. Wahlström T and Henriksson MA: Impact of MYC in regulation of tumor cell metabolism. Biochim Biophys Acta 1849: 563-569, 2015.

51. Fujiwara K, Yuwanita I, Hollern DP and Andrechek ER: Prediction and genetic demonstration of a role for activator E2Fs in Myc-induced tumors. Cancer Res 71: 1924-1932, 2011.

52. Wu L, de Bruin A, Wang H, Simmons T, Cleghorn W, Goldenberg LE, Sites E, Sandy A, Trimboli A, Fernandez SA, et al: Selective roles of E2Fs for ErbB2- and Myc-mediated mammary tumorigenesis. Oncogene 34: 119-128, 2015.
53. Liu X, Gao Y, Ye H, Gerrin S, Ma F, Wu Y, Zhang T, Russo J, Cai C, Yuan X, et al: Positive feedback loop mediated by protein phosphatase $1 \alpha$ mobilization of P-TEFb and basal CDK1 drives androgen receptor in prostate cancer. Nucleic Acids Res 45: 3738-3751, 2017.

54. Saatci Ö, Borgoni S, Akbulut Ö, Durmuş S, Raza U, Eyüpoğlu E, Alkan C, Akyol A, Kütük Ö, Wiemann S and Şahin Ö: Targeting PLK1 overcomes T-DM1 resistance via CDK1-dependent phosphorylation and inactivation of Bcl-2/xL in HER2-positive breast cancer. Oncogene 37: 2251-2269, 2018.

55. Diril MK, Ratnacaram CK, Padmakumar VC, Du T, Wasser M, Coppola V, Tessarollo L and Kaldis P: Cyclin-dependent kinase $1(\mathrm{Cdk} 1)$ is essential for cell division and suppression of DNA re-replication but not for liver regeneration. Proc Natl Acad Sci USA 109: 3826-3831, 2012.

56. Zhang P, Kawakami H, Liu W, Zeng X, Strebhardt K, Tao K, Huang $S$ and Sinicrope FA: Targeting CDK1 and MEK/ERK overcomes apoptotic resistance in BRAF-mutant human colorectal cancer. Mol Cancer Res 16: 378-389, 2018.

(i) () () This work is licensed under a Creative Commons

EY NG ND Attribution-NonCommercial-NoDerivatives 4.0 International (CC BY-NC-ND 4.0) License. 